\title{
Benchmarking services in Outpatient hysteroscopy (OPH): a quality improvement project
}

\author{
Ayesha Mahmud ${ }^{1}$, Paul Smith², and T Justin Clark ${ }^{2}$ \\ ${ }^{1}$ Royal Stoke University Hospital \\ ${ }^{2}$ Birmingham Womens Hospital
}

September 24, 2020

\begin{abstract}
Objective To develop a survey evaluating women's experience of outpatient hysteroscopy (OPH) to generate data for benchmarking services in the UK Design Quality improvement project and national survey. Setting 77 hospitals with OPH services collected data over two-months. Population 5151 women Methods The OPH-Patient Satisfaction Survey (OPH-PSS) was developed using a multi-disciplinary approach. Good practice guidance in hysteroscopy and existing survey's provided content for the survey. Pilot testing identified aspects of the women's OPH journey that contributed to a final survey that was rolled out nationally. Main outcome variable Adequacy of OPH services reflected in women's experience of their OPH journey and the quality of care being delivered. Results The majority $(3193,76 \%)$ of hysteroscopic procedures were diagnostic. Most women (4485, 87\%) received adequate information regarding OPH with 4581 (89\%) agreeing that analgesia was discussed. 5033 (97\%) felt involved in their care. Women commonly reported pain $(4490,87 \%)$, but $>50 \%$ regarded this as slight. 1 in 10 women felt anxious. 1217 (26\%) women experienced feeling faint. Overall, >90\% (4,867) of women considered the OPH service good. The mean score rating for overall level of care was considerably high $(9.7 / 10)$. Comparative pain scores for OPH vs the worst pain felt during a menstrual period showed $\mathrm{OPH}$ to be less painful, except for endometrial ablation $(\mathrm{P}=<0.001)$. Conclusion This novel survey, evaluating women's experience of OPH (OPH-PSS), provides a useful tool for benchmarking OPH services. Overall, the information provided to women and their subsequent experience of OPH is good, but pain is common.
\end{abstract}

\section{Objective}

To develop a survey evaluating women's experience of outpatient hysteroscopy (OPH) to generate data for benchmarking services in the UK

\section{Design}

Quality improvement project and national survey.

\section{Setting}

77 hospitals with OPH services collected data over two-months.

\section{Population}

5151 women

\section{Methods}

The OPH-Patient Satisfaction Survey (OPH-PSS) was developed using a multi-disciplinary approach. Good practice guidance in hysteroscopy and existing survey's provided content for the survey. Pilot testing identified aspects of the women's OPH journey that contributed to a final survey that was rolled out nationally.

\section{Main outcome variable}


Adequacy of OPH services reflected in women's experience of their OPH journey and the quality of care being delivered.

\section{Results}

The majority $(3193,76 \%)$ of hysteroscopic procedures were diagnostic. Most women $(4485,87 \%)$ received adequate information regarding OPH with $4581(89 \%)$ agreeing that analgesia was discussed. $5033(97 \%)$ felt involved in their care. Women commonly reported pain $(4490,87 \%)$, but $>50 \%$ regarded this as slight. 1 in 10 women felt anxious. $1217(26 \%)$ women experienced feeling faint. Overall, $>90 \%(4,867)$ of women considered the $\mathrm{OPH}$ service good. The mean score rating for overall level of care was considerably high $(9.7 / 10)$. Comparative pain scores for $\mathrm{OPH}$ vs the worst pain felt during a menstrual period showed $\mathrm{OPH}$ to be less painful, except for endometrial ablation $(\mathrm{P}=<0.001)$.

\section{Conclusion}

This novel survey, evaluating women's experience of OPH (OPH-PSS), provides a useful tool for benchmarking OPH services. Overall, the information provided to women and their subsequent experience of $\mathrm{OPH}$ is good, but pain is common.

Funding statement: The British Society for Gynaecological Endoscopy (BSGE) contributed £300 funding towards electronic data entry.

Keywords: Outpatient hysteroscopy, ambulatory, gynaecology, quality improvement, benchmarking, pain.

Tweetable abstract (110 characters): The development and distribution of a national survey to provide benchmarking data for outpatient hysteroscopy

\section{Introduction}

Outpatient hysteroscopy (OPH) is the cornerstone of modern-day ambulatory gynaecological surgery. ${ }^{1}$ Hysteroscopy is the gold standard test to diagnose endometrial and structural uterine cavity pathologies associated with abnormal uterine bleeding (AUB) and reproductive failure. Furthermore, newer miniature technologies, have facilitated operative $\mathrm{OPH}$, where many common uterine treatments can be conducted in the outpatient setting at the time of diagnosis; so-called "see and treat" practice; expanded to include procedures such as endometrial ablation, polypectomy and myomectomy. ${ }^{2}$

The safety, convenience and efficiency of this common ambulatory procedure is well recognised. ${ }^{2-4}$ However, as outpatient hysteroscopy is performed in conscious patients, the pain and acceptability of OPH has been thoroughly investigated and reported using a variety of measures such as pain scores and bespoke, qualitative questionnaires. ${ }^{5-8}$

A recent national survey of $\mathrm{OPH}$ practice in the United Kingdom highlighted several variations in $\mathrm{OPH}$ practice thereby raising questions about women's experience of $\mathrm{OPH} .{ }^{9}$ In this survey of 142 clinicians performing OPH, $85 \%$ of respondents reported routinely collecting patient feedback. However, $52 \%$ of these respondents reported using the NHS "Friends and family test", a measure that is inherently non-specific to $\mathrm{OPH}$. The survey also demonstrated that there was a lack of standardisation in the assessment of the patient experience of $\mathrm{OPH}$.

The lack of a uniformly accepted OPH tool to assess patient's experience of OPH precludes valid assessment of this common procedure, especially the comparative effectiveness of interventions such as surgical techniques, health technologies, and pharmacological agents in reducing pain and optimising patient experience.

Moreover, there have been concerns expressed from patient groups about the variation in the quality of OPH service delivery and women experiencing unacceptable pain during $\mathrm{OPH}$ with long-term consequences. ${ }^{10}$

We, therefore, developed a questionnaire to evaluate the patient's views and experience of OPH. Furthermore, we disseminated this tool across the UK to assess women's perspective of their experiences of the OPH and to generate data to benchmark $\mathrm{OPH}$ practice with the ultimate aim of improving $\mathrm{OPH}$ services and optimising the patient experience. 


\section{Methods}

Development of the OPH-PSS

In collaboration with a multi-disciplinary team of hysteroscopy experts (British Society for Gynaecological Endoscopy (BSGE)), a pilot OPH patient satisfaction survey (OPH-PSS) representing aspects of the OPH journey was created based on current RCOG (Royal College of Obstetricians and Gynaecologists) best practice guidance in $\mathrm{OPH}^{11}$ with content from existing hysteroscopy surveys. The various steps involved in the development of the OPH-PSS are shown in Figure 1.

The content for the survey was provided by BSGE members sharing copies of their local OPH questionnaires (4) and from conducting additional internet searches to identify a pool of existing patient experience questionnaires (8). This informed the creation of a draft survey, which was then reviewed by the research team and the hysteroscopy subcommittee of the BSGE and the BSGE Council. Duplicate information was removed as well as formatting and wording finalised for pilot testing.

\section{Pilot testing}

Pilot testing involved thirty women attending OPH services (Aug-Dec 2018) at two different hospital sites (Birmingham Women's and Children's NHS Foundation Trust and Walsall Healthcare NHS Trust) in the West Midlands region of the United Kingdom. Participation was voluntary, and all feedback was anonymous. Women were asked to reflect on the experience of the care they had received while completing the survey, and to provide feedback regarding its content, layout and format of the pilot survey. They were all asked if the survey represented aspects important to them and made suggestions for improvement. This informed successive revisions of the pilot survey until a final version was agreed. Hence, pilot testing helped provide an understanding of women's OPH journey and facilitated the modification of the pilot survey into its final form.

Four key themes representing women's OPH journey were identified (Figure 2). These included aspects of care representing the continuum of their OPH journey (before, during and after) and their overall experience. The Women's OPH journey model (Figure 2) was used as a template to draft and order the content of the final OPH-PSS. As a result, a two-page survey representing women's OPH journey was created, ready for national role out (Appendix S1). The final OPH-PSS was shared for feedback with over 100 nurse and medical OPH practitioners who were attending a national BSGE Ambulatory Care Network (ACN) meeting in March 2019 and a national role out to facilitate benchmarking of OPH experience was agreed by the ACN. Minor amendments to the content were made in response to the ACN feedback at this stage. This included deletion of one duplicate statement and addition of a box to input operator code for appraisal purposes.

\section{Setting}

All BSGE members were invited via email and through the BSGE website to participate in a national data collection programme using the OPH-PSS. Participating members were asked to collect data for all patients undergoing OPH in their units over two months (from October to November 2019).

\section{Data Collection}

Both electronic (Googleforms (B) and paper data collection were used to capture responses to the OPH-PSS. Participating units were advised to use electronic data input where possible but also given the option to post anonymised paper forms to the project team to optimise data collection where human resources to input data electronically were limited.

\section{Statistical analysis}

All statistical analysis was performed using SPSS ${ }^{\circledR}$ version 20 (Chicago, IL, USA). Simple frequency tables and proportions were used to present categorical variables. Pain and experience scores were presented as means, standard deviations and $95 \%$ confidence intervals. Following analysis to check the data was normally 
distributed, comparisons of pain scores between centres and procedure types were performed using the student t-test.

Results

A total of 5151 patient responses were received from 77 participating units. All data were collected on paper before electronic upload either by the local participating units (1550, 30\%) or following postal submission to the research project team $(3601,70 \%)$.

\section{Type of procedure}

The majority of the procedures $(3193,76 \%)$ were recorded as diagnostic (Table 1$)$. Hysteroscopic polypectomy was the most common operative procedure representing $713 / 1258,57 \%$ of such procedures. Where more than one type of procedure was undertaken, the procedure was categorised according to the following hierarchy: endometrial ablation $>$ myomectomy $>$ polypectomy $>$ insertion/retrieval IUS $>$ hysteroscopy $+/-$ biopsy.

\section{Procedural pain}

A comparison between the type of procedure and associated procedural pain is also reported in Table 1. The mean pain score for diagnostic hysteroscopy with or without endometrial biopsy was 5.2 / 10 . Hysteroscopic polypectomy was not associated with greater pain than diagnostic procedures; however, hysteroscopic myomectomy and endometrial ablation were associated with significantly higher pain scores.

\section{Before hysteroscopy}

Most women $(4485,87 \%)$ received written information before their appointment. The written information was considered clear and understandable by 3 out of every 4 women. Most women (4200, 82\%) received written information about taking analgesia. Of these, 1 in 5 (18\%) did not take any analgesia. The majority of women $(4103,95 \%)$ considered the waiting area, reception and facilities to be at least good, with more than $45 \%$ of women considering them excellent (Table 2).

During hysteroscopy (About your consultation today)

Women provided feedback regarding different aspects of their consultation (Table 3). Almost all women $(5113,98 \%)$ agreed that staff provided understandable information and that they were able to ask questions and to discuss any worries. Similarly, the vast majority $(4581,89 \%)$, of women agreed that they were offered an opportunity to discuss pain relief.

The majority of women $(5113,98 \%)$ agreed that their questions were satisfactorily answered. In addition, $5033(97 \%)$ of women agreed that they felt involved in the decisions regarding their care. Nearly all women agreed that they were treated with respect and dignity and given privacy during their consultation. Similarly, almost all women agreed that all aspects of their care were dealt with confidentially. Most women (5099, $>90 \%$ ) strongly agreed that staff were courteous and polite. Similarly, the vast majority of women agreed that they were advised on their plan for recovery and management (Table 3).

Your experience (considering your expectations of today's consultation)

Taking into account the information that women were provided from the appointment letter or patient information leaflet (PIL) before their hysteroscopy, they were asked about their procedural experience (Table 4). Half of all, women (53\%) did not feel any distress during their hysteroscopy. Of those women experiencing distress, most, 6 out of 10, considered the degree of distress as slight. Overall, just over 1 in 10 women experienced at least some distress and nearly 5 in 100 women experienced distress most or all of the time. Most women, $>85 \%$, experienced pain during hysteroscopy. Of those women experiencing pain, just over half considered the degree of pain as slight. Overall, $40 \%$ of women experienced at least some pain, and $15 \%$ of women experienced pain most or all of the time. $70 \%$ of women felt mostly or constantly in control, whilst 1 in 20 women did not feel any semblance of control. 
Most women, $>60 \%$, did not feel any embarrassment and of those women who did, most considered the degree of embarrassment as slight. Most women $(>70 \%)$, admitted to feeling anxious, most considered the degree of anxiety as slight. Just over 1 in 10 women experienced anxiety most or all of the time. Nearly $24 \%$ of women undergoing OPH felt faint, although most only felt this slightly (Table 4).

Your overall experience

Most women, $>90 \%$, considered the service as at least good with $>80 \%$ considering the service excellent. Only 1 in 100 women considered the service as either fair, poor or very poor. When asked if they would choose the outpatient setting if in the same situation again, $90 \%$ agreed, with nearly 7 out of 10 women strongly agreeing. Of those women not agreeing to choose the outpatient setting if in the same situation again, the majority, 6 out of 10, were unsure, neither agreeing nor disagreeing. Approximately 3 in 100 women would not agree to choose the outpatient setting if in the same situation again. The mean score rating for the overall level of care was 9.7/10. (See supplementary information Tables 6,7 and 8)

Procedural pain compared to menstrual pain

Women rated the discomfort or pain experienced during $\mathrm{OPH}$ and that during a menstrual period on a scale of 0-10 (none-worst). On comparison, the mean pain score for an OPH procedure was less than the worst level of pain or discomfort experienced during a menstrual period (Table 5). Data was analysed to assess pain scores specific to the type of OPH procedure. It was observed that the mean pain score for an $\mathrm{OPH}$ procedure was less than the worst level of pain or discomfort experienced during a menstrual period for all outpatient hysteroscopic procedures except for outpatient endometrial ablation (Table 5).

\section{Discussion}

\section{Main findings}

A new OPH patient satisfaction survey (OPH-PSS) was developed in collaboration with the BSGE, with multi-disciplinary input and patient and public involvement (PPI). Women provided feedback and insight regarding their $\mathrm{OPH}$ journey leading to the development of a new standardised assessment tool suitable for benchmarking OPH services nationally. In two months, 5151 completed responses were received from 77 Units across the UK. This large return reflects the high prevalence of the procedure in contemporary gynaecological practice and infers the acceptability and utility of the developed survey tool. The majority of procedures were recorded as diagnostic. The survey was designed to assess all aspects of the patients $\mathrm{OPH}$ journey, including pre, peri and post-procedural experiences. The global rating of overall care was extremely high, with a mean score rating of 9.7 out of 10 . Over $90 \%$ of women considered the OPH service they experienced as at least good, with over $80 \%$ considering the service excellent. Consistent with these findings, $90 \%$ agreed that they would choose the outpatient setting if the same situation arose again, with nearly 7 out of 10 women strongly agreeing. These findings suggest that for the vast majority of women, $\mathrm{OPH}$ is a safe, tolerable experience. This conclusion is further strengthened by the finding that overall, the mean pain score for $\mathrm{OPH}$ was less than the worst level of pain or discomfort experienced during a menstrual period.

The mean pain score for diagnostic hysteroscopy with or without endometrial biopsy was $5.2 / 10$, and this intensity of pain was less than the worst pain experienced by women during their menstrual periods. It should be noted the most common operative procedure of polypectomy was not associated with greater pain than diagnostic procedures. Procedure specific data for other OPH procedures such as myomectomy and endometrial ablation were too limited to draw any conclusions. Whilst most women experienced pain, over half considered this to be slight. However, $15 \%$ of women reported feeling pain nearly all the time. Whilst women's experience of $\mathrm{OPH}$ was variable, most did not experience substantial levels of pain, distress, anxiety, or embarrassment and felt in control. Vaso-vagal reactions from stimulation of the cervix are one of the most common side-effects of $\mathrm{OPH}{ }^{11}$, but $70 \%$ of respondents did not report feeling faint, and most women that did report this symptom felt the intensity as slight.

Before their consultation, the majority of women reported receiving written information in a clear and 
understandable format that included material about taking analgesia. These findings show that current patient information leaflets are fit for purpose. Standardised patient information leaflets (PILs) are available via the $\mathrm{RCOG}^{12}$ and newer alternative video-information resources are becoming available. ${ }^{13}$ It is important that such resources are updated regularly to reflect current guidance, which may change as more evidence becomes available.

Overall, almost all women felt that aspects of their consultation were dealt with appropriately. Communication seemed of a high standard, with most women reporting feeling at ease, with their concerns being addressed and staff treating them with respect and dignity. The vast majority of women had the opportunity to discuss pain relief and were given adequate post-procedural advice.

\section{Revised final OPH-PSS}

The results of the OPH-PSS survey were shared for feedback with over 150 nurse and medical OPH practitioners who were attending a national BSGE Ambulatory Care Network (ACN) meeting in March 2020. Participants suggested a minor amendment to the location of the patient procedural information collection box. This was moved from the back of the survey to the front to avoid the risk of missing data during future data collection. Generally, they found the survey easy to use for data collection.

\section{Strengths and limitations}

The strength of this project lies in its women-centred, multi-disciplinary approach with PPI involvement in the development of a new OPH-PSS. The tool was designed to be comprehensive, covering all aspects of the $\mathrm{OPH}$ experience and not simply restricting evaluation to the procedure itself. In this way, valid information was acquired pertaining to the quality of care before, during and after the procedure. Moreover, the sample is, to our knowledge, by far the largest obtained evaluating women's experience of OPH. The large sample allowed the generation of precise estimates for various outcomes and with 77 different UK centres providing data enhances the generalisability of these findings.

Although pilot testing was able to rectify most issues with the OPH-PSS procedural information was found to be missing in $680(13.2 \%)$ submitted forms. For the purpose of analysis, it was assumed that all patients, where the specific hysteroscopic procedure was not defined, had a diagnostic hysteroscopy procedure performed. This assumption was conservative but may have led to an overestimate of pain associated with diagnostic procedures. Furthermore, OPH alone was not a response option on the survey, rather OPH with or without an endometrial biopsy. Endometrial biopsy is known to be more painful than $\mathrm{OPH}^{14}$, and so again, the average pain associated with diagnostic OPH may have been exaggerated. To avoid similar issues in the future, the final OPH-PSS has been modified to include procedural details at the beginning of the survey for staff to complete before seeking patient feedback, and diagnostic OPH without endometrial biopsy is a specific response category.

\section{Implications for clinical practice and research}

The modified survey should be made readily visible (for example on the BSGE website for download [https://www.bsge.org.uk]) and available for use by $\mathrm{OPH}$ units to allow comparison and benchmarking. In this way, areas of good practice can be highlighted, and explanations for excellent performance explored and shared with the wider gynaecological community. Conversely, areas of sub-optimal performance can be more readily identified, enquiries instigated and remedial measures put in place, such as rectifying staffing, infrastructure or equipment deficiencies, changing appointment schedules, improving patient information and offering additional clinician training, as appropriate.

The national survey should be repeated within the next 2 to 5 years to evaluate whether the overall practice has improved as gauged from the mean scores/responses acquired compared to the index survey conducted at the end of 2019. Further work is needed to produce the OPH-PSS in other languages to ensure that the experience of all the UK community is obtained and to allow the use of the survey internationally enhancing generalisability further and acquiring global perspectives. The OPH-PSS should also be formatted electronically for completion to aid wider dissemination. 
The exploration of potential reasons behind the individual scores of participating women was beyond the scope of this project. However, qualitative research could be targeted at women reporting poor experiences, especially relating to the experience of unacceptable pain during hysteroscopy.

\section{Conclusion}

We have developed a new women-centred outpatient hysteroscopy patient satisfaction survey (OPH-PSS) suitable for routine use in outpatient hysteroscopy. This survey has provided important insight towards women's experiences of OPH. It remains a useful resource for clinicians practising $\mathrm{OPH}$ and for benchmarking performance across different units. This will allow centres to not only collect and report data on patient satisfaction for their OPH services but also to help identify gaps for improving services and be used for local appraisal and training. Locally, units may find it helpful to integrate the questionnaire within their routine $\mathrm{OPH}$ service structure.

\section{Disclosure of Interests}

AM, PS and TJC have nothing to disclose. Completed disclosure of interest forms will be available to view online as supporting information.

Contribution to Authorship

TJC conceived the study. AM planned and carried out the project under TJC's guidance. PS performed the statistical analysis. AM, PS and TJC carried out data interpretation. AM drafted the manuscript. TJC and PS provided comments and contributed to the development of the final version of the manuscript.

Details of Ethics Approval

Formal ethical approval was not sought because this was a service improvement project and questionnaires were fully anonymised.

\section{Funding}

The BSGE contributed $£ 300$ funding towards electronic data entry.

\section{Acknowledgements}

The authors would like to acknowledge the contribution of the women that participated in this project. We would also like to thank the BSGE council and BSGE members that provided critical feedback and input throughout this project.

\section{References}

1. NHS Digital, Hospital Admitted Patient Care Activity 2018-19 - NHS Digital. NHS Digital. [https://digital.nhs.uk/data-and-information/publications/statistical/hospital-admitted-patientcare-activity/2018-19]. Accessed September 16, 2020.

2. Clark TJ, Gupta JK. Handbook of Outpatient Hysteroscopy: A Complete Guide to Diagnosis and Therapy. Vol. 1. Boca Raton, FL: CRC Press, 2005.

3. Saridogan E, Tilden D, Sykes D, Davis N, Subramanian D. Cost-Analysis Comparison of Outpatient See-and-Treat Hysteroscopy Service with Other Hysteroscopy Service Models. J Minim Invasive Gynecol . 2010;17(4):518-525. doi:10.1016/j.jmig.2010.03.009

4. Kremer C. Patient satisfaction with outpatient hysteroscopy versus day-case hysteroscopy: randomised controlled trial. BMJ . 2000;320(7230):279-282. doi:10.1136/bmj.320.7230.279

5. Cooper N, Smith P, Khan K, Clark T. Vaginoscopic approach to outpatient hysteroscopy: a systematic review of the effect on pain. BJOG: An International Journal of Obstetrics 8 Gynaecology . 2010;117(9):1164-1164. doi:10.1111/j.1471-0528.2010.02613.x

6. Smith P, Kolhe S, O'Connor S, Clark T. Vaginoscopy Against Standard Treatment: a randomised controlled trial. BJOG: An International Journal of Obstetrics \& Gynaecology . 2019;126(7):891-899. doi:10.1111/1471-0528.15665 
7. Clark T, Samuels N, Malick S, Middleton L, Daniels J, Gupta J. Bipolar Radiofrequency Compared With Thermal Balloon Endometrial Ablation in the Office: A Randomized Controlled Trial. Obstetrics \&3 Gynecology . 2011;117(5):1228. doi:10.1097/aog.0b013e3182175ba5

8. Cooper N, Clark T, Middleton L et al. Outpatient versus inpatient uterine polyp treatment for abnormal uterine bleeding: randomised controlled non-inferiority study. BMJ . 2015;350(mar23 6):h1398-h1398. doi:10.1136/bmj.h1398

9. Mahmud A, Waters N, Clark T. A UK-based National audit of Outpatient hysteroscopy services. 2018. Unpublished

10. Hysteroscopy Action [Internet]. 2020 [https://www.hysteroscopyaction.org.uk/]. Accessed September $13,2020$.

11. Clark TJ, Cooper NA, Kremer C. Best practice in outpatient hysteroscopy. RCOG Press Greentop Guideline No. 59. [https://www.rcog.org.uk/en/guidelines-researchservices/guidelines/gtg59/]. Accessed September 13, 2020.

12. Outpatient hysteroscopy. Royal College of Obstetricians \& Gynaecologists. [https://www.rcog.org.uk/en/patients/patient-leaflets/outpatient-hysteroscopy/]. Accessed September 13, 2020.

13. Outpatient Hysteroscopy - AGES. Australasian Gynaecological Endoscopy \& Surgery [Internet]. 2020. [https://ages.com.au/video/outpatient-hysteroscopy/]. Accessed September 13, 2020.

14. Abbott J, Hawe J, Phillips G. A prospective evaluation of pain and acceptability during outpatient flexible hysteroscopy and endometrial biopsy. Gynaecological Endoscopy . 2002;11(1):37-41. doi:10.1046/j.0962-1091.2002.00489.x

Table 1: Comparison between type of procedure and procedural pain $(N=5151)$

\begin{tabular}{|c|c|c|c|c|c|c|c|}
\hline $\begin{array}{l}\text { Type of } \\
\text { procedure }\end{array}$ & $\begin{array}{l}\text { Number } \\
(\%)\end{array}$ & $\begin{array}{l}\text { Mean pain } \\
\text { during } \\
\text { procedure }\end{array}$ & $\begin{array}{l}95 \% \\
\text { confidence } \\
\text { interval }\end{array}$ & $\begin{array}{l}95 \% \\
\text { confidence } \\
\text { interval }\end{array}$ & $\begin{array}{l}\text { Standard } \\
\text { Deviation } \\
\text { (SD) }\end{array}$ & $\begin{array}{l}\text { Mean } \\
\text { difference } \\
\text { from } \\
\text { control }\end{array}$ & $\begin{array}{l}P \text { value } \\
\text { compared } \\
\text { to control }\end{array}$ \\
\hline & & & $\begin{array}{l}\text { lower } \\
\text { bound }\end{array}$ & $\begin{array}{l}\text { upper } \\
\text { bound }\end{array}$ & & & \\
\hline $\begin{array}{l}\text { Diagnostic } \\
\text { hys- } \\
\text { teroscopy } \\
+/- \\
\text { biopsy }\end{array}$ & $\begin{array}{l}3893 \\
(75.6)\end{array}$ & 5.2 & 5.12 & 5.29 & 2.724 & Control & Control \\
\hline \multicolumn{2}{|c|}{$\begin{array}{l}\text { biopsy } \\
\text { Insertion/Retilev(d.7) } \\
\text { of }\end{array}$} & 5.16 & 4.91 & 5.41 & 2.654 & -0.039 & 0.776 \\
\hline \multicolumn{8}{|c|}{$\begin{array}{l}\text { IUCD*/Mirena } \\
\text { or }\end{array}$} \\
\hline \multicolumn{2}{|c|}{$\begin{array}{l}\text { Hysteroscopic } 713(13.8) \\
\text { polypec- } \\
\text { tomy }\end{array}$} & 5.1 & 4.91 & 5.29 & 2.59 & -0.102 & 0.358 \\
\hline \multicolumn{2}{|c|}{ Myomectomy30 (0.6) } & 6.37 & 5.37 & 7.36 & 2.671 & 1.164 & 0.02 \\
\hline \multicolumn{8}{|c|}{ Ablation } \\
\hline $\begin{array}{l}\text { Other } \\
\text { (RPOC***, } \\
\text { adhesiol- } \\
\text { ysis) }\end{array}$ & $4(0.1)$ & 6.25 & 4.25 & 8.25 & 1.258 & 1.047 & 0.442 \\
\hline
\end{tabular}


*Intrauterine Contraceptive Device

**Intrauterine System

*** Retained Products of Conception

Table 2: Women's responses to questions 'Before your Consultation' ( $n=5151$ )

\begin{tabular}{|c|c|c|c|}
\hline $\begin{array}{l}\text { Before your } \\
\text { consultation }\end{array}$ & $\begin{array}{l}\text { Before your } \\
\text { consultation }\end{array}$ & $\begin{array}{l}\text { Before your } \\
\text { consultation }\end{array}$ & $\begin{array}{l}\text { Before your } \\
\text { consultation }\end{array}$ \\
\hline Questions & Response options & $\begin{array}{l}\text { Number of } \\
\text { responses (n) }\end{array}$ & Percentage (\%) \\
\hline \multirow{4}{*}{$\begin{array}{l}\text { Did you receive any } \\
\text { written information (e.g. } \\
\text { a leaflet or instructions } \\
\text { about where to acquire } \\
\text { information e.g. on-line) } \\
\text { prior to your } \\
\text { appointment? }\end{array}$} & Yes & 4485 & 87.1 \\
\hline & No & 574 & 11.1 \\
\hline & $\begin{array}{l}\text { Yes; No (both selected in } \\
\text { error) }\end{array}$ & 4 & 0.1 \\
\hline & Not answered & 88 & 1.7 \\
\hline \multirow{7}{*}{$\begin{array}{l}\text { Did you feel that the } \\
\text { information was clear } \\
\text { and understandable? (not } \\
\text { applicable if you answered } \\
\text { No to the question above) }\end{array}$} & $\begin{array}{l}\text { Yes - I knew what to } \\
\text { expect }\end{array}$ & 3923 & 76.2 \\
\hline & Yes - to some extent & 591 & 11.5 \\
\hline & Not too Sure & 88 & 1.7 \\
\hline & $\begin{array}{l}\text { No - wish I knew what to } \\
\text { expect }\end{array}$ & 46 & 0.9 \\
\hline & No - it was not useful & 14 & 0.3 \\
\hline & Not Applicable & 256 & 5 \\
\hline & Not answered & 233 & 4.5 \\
\hline \multirow{5}{*}{$\begin{array}{l}\text { Did you receive advice to } \\
\text { take painkillers before the } \\
\text { appointment? }\end{array}$} & Yes - took some & 3444 & 66.9 \\
\hline & Yes - did not take any & 756 & 14.7 \\
\hline & No - wish I had & 341 & 6.6 \\
\hline & No - no need & 530 & 10.3 \\
\hline & Not answered & 80 & 1.5 \\
\hline \multirow{6}{*}{$\begin{array}{l}\text { What did you think of the } \\
\text { waiting area, reception } \\
\text { and facilities? }\end{array}$} & Excellent & 2417 & 46.9 \\
\hline & Very Good & 1686 & 32.7 \\
\hline & Good & 765 & 14.9 \\
\hline & Fair & 192 & 3.7 \\
\hline & Poor & 8 & 0.2 \\
\hline & Not answered & 83 & 1.6 \\
\hline
\end{tabular}

Table 3: Women's responses to questions 'About your Consultation' ( $n=5151)$ 


\begin{tabular}{|c|c|c|c|}
\hline $\begin{array}{l}\text { About your } \\
\text { consultation }\end{array}$ & $\begin{array}{l}\text { About your } \\
\text { consultation }\end{array}$ & $\begin{array}{l}\text { About your } \\
\text { consultation }\end{array}$ & $\begin{array}{l}\text { About your } \\
\text { consultation }\end{array}$ \\
\hline Questions & Response options & $\begin{array}{l}\text { Number of } \\
\text { responses (n) }\end{array}$ & Percentage (\%) \\
\hline \multirow{6}{*}{$\begin{array}{l}\text { Staff explained things in } \\
\text { a way I could easily } \\
\text { understand. }\end{array}$} & Strongly Agree & 4630 & 89.9 \\
\hline & Agree & 483 & 9.4 \\
\hline & Neither Agree or Disagree & 14 & 0.3 \\
\hline & Disagree & 2 & 0 \\
\hline & Strongly Disagree & 3 & 0.1 \\
\hline & Not answered & 19 & 0.4 \\
\hline \multirow{6}{*}{$\begin{array}{l}\text { I felt able to ask } \\
\text { questions and to discuss } \\
\text { any worries. }\end{array}$} & Strongly Agree & 4538 & 88.1 \\
\hline & Agree & 521 & 10.1 \\
\hline & Neither Agree or Disagree & 21 & 0.4 \\
\hline & Disagree & 11 & 0.2 \\
\hline & Strongly Disagree & 3 & 0.1 \\
\hline & Not answered & 57 & 1.1 \\
\hline \multirow{6}{*}{$\begin{array}{l}\text { I was offered an } \\
\text { opportunity to discuss } \\
\text { pain relief. }\end{array}$} & Strongly Agree & 3655 & 71 \\
\hline & Agree & 926 & 18 \\
\hline & Neither Agree or Disagree & 390 & 7.6 \\
\hline & Strongly Disagree & 15 & 0.3 \\
\hline & Disagree & 99 & 1.9 \\
\hline & Not answered & 66 & 1.3 \\
\hline \multirow{6}{*}{$\begin{array}{l}\text { My questions were } \\
\text { answered to my } \\
\text { satisfaction. }\end{array}$} & Strongly Agree & 4321 & 83.9 \\
\hline & Agree & 707 & 13.7 \\
\hline & $\begin{array}{l}\text { Neither Agree or } \\
\text { Disagree }\end{array}$ & 52 & 1 \\
\hline & Strongly Disagree & 4 & 0.1 \\
\hline & Disagree & 4 & 0.1 \\
\hline & Not answered & 63 & 1.2 \\
\hline \multirow{6}{*}{$\begin{array}{l}\text { I felt involved in the } \\
\text { decisions regarding my } \\
\text { care. }\end{array}$} & Strongly Agree & 4298 & 83.4 \\
\hline & Agree & 735 & 14.3 \\
\hline & Neither Agree or Disagree & 70 & 1.4 \\
\hline & Disagree & 8 & 0.2 \\
\hline & Strongly Disagree & 4 & 0.1 \\
\hline & Not answered & 36 & 0.7 \\
\hline \multirow{5}{*}{$\begin{array}{l}\text { I was treated with respect } \\
\text { and dignity. }\end{array}$} & Strongly Agree & 4745 & 92.1 \\
\hline & Agree & 332 & 6.4 \\
\hline & Neither Agree or Disagree & 8 & 0.2 \\
\hline & Disagree & 2 & 0 \\
\hline & Strongly Disagree & 2 & 0 \\
\hline
\end{tabular}




\begin{tabular}{llll}
\hline $\begin{array}{l}\text { About your } \\
\text { consultation }\end{array}$ & $\begin{array}{l}\text { About your } \\
\text { consultation }\end{array}$ & $\begin{array}{l}\text { About your } \\
\text { consultation }\end{array}$ & $\begin{array}{l}\text { About your } \\
\text { consultation }\end{array}$ \\
\hline \multirow{4}{*}{$\begin{array}{l}\text { I was given enough } \\
\text { privacy. }\end{array}$} & Not answered & 62 & 1.2 \\
& Strongly Agree & 4724 & 91.7 \\
& Agree & 370 & 7.2 \\
& Neither Agree or Disagree & 7 & 0.1 \\
& Disagree & 4 & 0.1 \\
& Strongly Disagree & 2 & 0 \\
All aspects of my care & Not answered & 44 & 0.9 \\
were dealt with & Strongly Agree & 4637 & 90 \\
confidentially. & & & \\
& & 429 & 8.3 \\
& Agree & 22 & 0.4 \\
Neither Agree or Disagree & 1 & 0 \\
The staff were courteous & Strongly Agree & 62 & 12 \\
and polite. & Strongly Disagree & 4637 & 90 \\
& Not answed & 4864 & 94.4 \\
& Agree & 235 & 4.6 \\
Neither Agree or Disagree & 4 & 0.1 \\
regarding my recovery & 1 & 0 \\
and management plan. & Strongly Agree & 1 & 0 \\
& & 46 & 0.9 \\
& Agree & 4413 & 85.7 \\
& Neither Agree or Disagree & 82 & \\
& Disagree & 9 & 11.2 \\
& Strongly Disagree & 5 & 1.6 \\
& Not answered & 65 & 0.2 \\
& Not answered & & 1.3 \\
\hline
\end{tabular}

Table 4: Women's responses to questions 'Your experience' ( $n=5151)$

\begin{tabular}{llll}
\hline YOUR & YOUR & YOUR & YOUR \\
EXPERIENCE & EXPERIENCE & EXPERIENCE & EXPERIENCE \\
(CONSIDERING & (CONSIDERING & (CONSIDERING & (CONSIDERING \\
YOUR & YOUR & YOUR & YOUR \\
EXPECTATIONS & EXPECTATIONS & EXPECTATIONS & EXPECTATIONS \\
OF TODAY'S & OF TODAY'S & OF TODAY'S & OF TODAY'S \\
CONSULTATION) & CONSULTATION) & CONSULTATION) & CONSULTATION) \\
\hline Questions & Response options & Number of & Percentage (\%) \\
& & responses (n) & \\
Did you feel distressed? & Not at all & 2747 & 53.3 \\
& Slightly & 1591 & 30.9 \\
& Somewhat & 429 & 8.3 \\
& Mostly & 161 & 3.1 \\
& Constantly & 63 & 1.2
\end{tabular}




\begin{tabular}{|c|c|c|c|}
\hline YOUR & YOUR & YOUR & YOUR \\
\hline EXPERIENCE & EXPERIENCE & EXPERIENCE & EXPERIENCE \\
\hline (CONSIDERING & (CONSIDERING & (CONSIDERING & (CONSIDERING \\
\hline YOUR & YOUR & YOUR & YOUR \\
\hline EXPECTATIONS & EXPECTATIONS & EXPECTATIONS & EXPECTATIONS \\
\hline OF TODAY'S & OF TODAY'S & OF TODAY'S & OF TODAY'S \\
\hline \multirow[t]{2}{*}{ CONSULTATION) } & CONSULTATION) & CONSULTATION) & CONSULTATION) \\
\hline & Not answered & 160 & 3.1 \\
\hline \multirow[t]{7}{*}{ Did you feel pain? } & Not at all & 464 & 9 \\
\hline & Slightly & 2456 & 47.7 \\
\hline & Somewhat & 1247 & 24.2 \\
\hline & Mostly & 643 & 12.5 \\
\hline & Constantly & 144 & 2.8 \\
\hline & Not answered & 197 & 3.8 \\
\hline & Not answered & 233 & 4.5 \\
\hline \multirow[t]{6}{*}{ Did you feel in control? } & Not at all & 276 & 5.4 \\
\hline & Slightly & 420 & 8.2 \\
\hline & Somewhat & 550 & 10.7 \\
\hline & Mostly & 1361 & 26.4 \\
\hline & Constantly & 2282 & 44.3 \\
\hline & Not answered & 262 & 5.1 \\
\hline \multirow{6}{*}{$\begin{array}{l}\text { Did you feel } \\
\text { embarrassed? }\end{array}$} & Not at all & 3345 & 64.9 \\
\hline & Slightly & 1120 & 21.7 \\
\hline & Somewhat & 338 & 6.6 \\
\hline & Mostly & 89 & 1.7 \\
\hline & Constantly & 56 & 1.1 \\
\hline & Not answered & 203 & 3.9 \\
\hline \multirow[t]{6}{*}{ Did you feel anxious? } & Not at all & 1257 & 24.4 \\
\hline & Slightly & 2314 & 44.9 \\
\hline & Somewhat & 799 & 15.5 \\
\hline & Mostly & 405 & 7.9 \\
\hline & Constantly & 219 & 4.3 \\
\hline & Not answered & 157 & 3.1 \\
\hline \multirow[t]{6}{*}{ Did you feel faint } & Not at all & 3762 & 73 \\
\hline & Slightly & 830 & 16.1 \\
\hline & Somewhat & 255 & 5 \\
\hline & Mostly & 108 & 2.1 \\
\hline & Constantly & 24 & 0.5 \\
\hline & Not answered & 172 & 3.3 \\
\hline
\end{tabular}

Table 5: Pain experienced with outpatient hysteroscopy compared to the worst level of discomfort or pain experienced during a menstrual period $(n=5151)$

What would be the worst level of discomfort or pain you might experience (or used to experience) during a period on a scal 
What would be the worst level of discomfort or pain you might experience (or used to experience) during a period on a scal What level of discomfort or pain you experienced during the procedure on the same scale of $0-10$ :

\section{Hosted file}

Figure 1.pdf available at https://authorea.com/users/361559/articles/482924-benchmarkingservices-in-outpatient-hysteroscopy-oph-a-quality-improvement-project

\section{Hosted file}

Figure 2.pdf available at https://authorea.com/users/361559/articles/482924-benchmarkingservices-in-outpatient-hysteroscopy-oph-a-quality-improvement-project 